\title{
Measles virus infection results in suppression of both innate and adaptive immune responses to secondary bacterial infection
}

\author{
Mark K. Slifka, ${ }^{1}$ Dirk Homann, ${ }^{2}$ Antoinette Tishon, ${ }^{2}$ Robb Pagarigan, ${ }^{2}$ \\ and Michael B.A. Oldstone ${ }^{2}$ \\ ${ }^{1}$ Oregon Health and Science University Vaccine and Gene Therapy Institute, Beaverton, Oregon, USA \\ ${ }^{2}$ The Scripps Research Institute, Division of Virology, Department of Neuropharmacology, La Jolla, California, USA
}

\begin{abstract}
Among infectious agents, measles virus (MV) remains a scourge responsible for 1 million deaths per year and is a leading cause of childhood deaths in developing countries. Although MV infection itself is not commonly lethal, MV-induced suppression of the immune system results in a greatly increased susceptibility to opportunistic bacterial infections that are largely responsible for the morbidity and mortality associated with this disease. Despite its clinical importance, the underlying mechanisms of MV-induced immunosuppression remain unresolved. To begin to understand the basis of increased susceptibility to bacterial infections during MV infection, we inoculated transgenic mice expressing the MV receptor, CD46, with MV and Listeria monocytogenes. We found that MV-infected mice were more susceptible to infection with Listeria and that this corresponded with significantly decreased numbers of macrophages and neutrophils in the spleen and substantial defects in IFN- $\gamma$ production by $\mathrm{CD}^{+} \mathrm{T}$ cells. The reduction in $\mathrm{CD} 11 \mathrm{~b}^{+}$macrophages and IFN- $\gamma-$ producing $\mathrm{T}$ cells was due to reduced proliferative expansion and not to enhanced apoptosis or to altered distribution of these cells between spleen, blood, and the lymphatic system. These results document that MV infection can suppress both innate and adaptive immune responses and lead to increased susceptibility to bacterial infection.
\end{abstract}

J. Clin. Invest. 111:805-810 (2003). doi:10.1172/JCI200313603.

\section{Introduction}

Because of the inability to implement an effective vaccination program, measles virus (MV) epidemics still rage across many developing countries, infecting approximately 40 million people and resulting in nearly 1 million deaths annually (1-4). MV infection is often associated with a generalized state of immunosuppression $(1,2,4-7)$, resulting in increased susceptibility to secondary infections that can have a substantial effect not only on the health but in some cases on the survival of the infected individual (8).

To better understand the mechanisms involved with MV-induced immunosuppression, we used transgenic mice (YAC-CD46) expressing a full-length human CD46 genomic clone that allows for viral replication and analysis of MV pathogenesis (7, 9). After intraperitoneal or intravenous inoculation, infectious $\mathrm{MV}$ can be recovered from $\mathrm{CD}^{+} \mathrm{T}$ cells, $\mathrm{CD} 4^{+} \mathrm{T}$ cells,

Received for publication June 22, 2001, and accepted in revised form January 28, 2003.

Address correspondence to: Michael B.A. Oldstone, The Scripps Research Institute, Division of Virology, Department of

Neuropharmacology, 10550 North Torrey Pines Road, La Jolla, California 92037, USA. Phone: (858) 784-8054;

Fax: (858) 784-9981; E-mail: mbaobo@scripps.edu.

Conflict of interest: The authors have declared that no conflict of interest exists.

Nonstandard abbreviations used: measles virus (MV); Listeria monocytogenes (LM).
$B$ cells, and macrophages by cocultivation on susceptible feeder cells. Moreover, MV RNA and proteins were expressed in the CNS, cervical, mesenteric, and peribronchial lymph nodes, Peyer's patches, spleen, and peribronchial endothelial cells $(7,10)$ (our unpublished data). In our analysis of secondary bacterial infection, we used Listeria monocytogenes (LM), a gram-positive intracellular bacterium. Although other microbes such as Mycobacterium tuberculosis and Staphylococcus aureus are most frequently associated with complications of MV infection $(1,2)$, we chose LM in this initial study because of its ease of handling, its low biohazard classification, and our familiarity with the LM model $(11,12)$ and because LM has been reported as an emerging cause of human infections (13), especially among immunocompromised individuals (14). LM was also chosen for this study because both innate immunity and adaptive immune responses play clearly defined roles in the control of this infection, thus providing an opportunity to simultaneously examine MV-associated effects on both these arms of the immune response to a secondary bacterial infection. For instance, innate effector cells - including activated macrophages, NK cells, and neutrophils - provide the first line of defense against LM infection (15). However, sterilizing immunity and protection from reinfection requires effective $T$ cell-mediated immune responses (16-19) and perhaps antibodies $(20,21)$. 
In this report, we examined the effects of concurrent $\mathrm{MV}$ infection on the host immune response to a bacterial infection by LM. Concurrent MV infection resulted in the suppression of innate immunity, as shown by the decreased accumulation of macrophages and neutrophils in the spleen, a major site of LM infection and replication. In addition, MV infection resulted in a decreased adaptive immune response, as indicated by a lower frequency of IFN- $\gamma$-producing CD $4^{+} \mathrm{T}$ cells after concurrent LM infection. Together, these MV-associated defects in innate and adaptive immune responses resulted in a decreased ability to clear the bacterial infection. Such data on how MV infection suppresses antibacterial immune responses should allow a better understanding of MV pathogenesis in infected humans and aid in the development of improved strategies for treatment.

\section{Methods}

Mice. The generation of the YAC-CD46 transgenic mouse line on the FVB/N background has been described in detail (7). Mice were bred at The Scripps Research Institute, screened for expression of the CD46 transgene (7), and used in the experiments at 7-12 weeks of age.

$M V$ and $L M$ infection of mice. YAC-CD46 transgenic mice were infected intravenously with $1 \times 10^{6}$ PFUs of the Edmonston strain of measles virus $(7,22)$. Five days after MV infection, mice were coinfected with $2 \times 10^{3}$ CFUs of LM strain 10403s (12). LM CFUs were determined by homogenization of infected tissues in sterile $\mathrm{H}_{2} \mathrm{O}$ containing $1 \%$ Triton $\mathrm{X}-100$ followed by plating dilutions of homogenate onto brain-heart infusion plates. Colonies were scored after 24 hours of growth at $37^{\circ} \mathrm{C}$.

Flow cytometry and intracellular cytokine staining. Specific cell types in the spleen were identified using the following antibodies: macrophages (CD11b), dendritic cells (CD11c), NK cells (DX5 $\left.{ }^{+} \mathrm{CD}^{-}\right)$, neutrophils (Gr- $\left.1^{+} \mathrm{CD}^{-}\right)$, B cells (B220), and T cells (CD4 or CD8). All antibodies were purchased from Pharmingen (San Diego, California, USA).

Annexin V staining. Single-cell suspensions obtained from spleens were stained for surface antigens (CD4, CD8, etc.), washed, and subsequently incubated for 15 minutes with Annexin V FITC and 7AAD according to the manufacturer's recommendations (Pharmingen). After staining, cells were immediately acquired without further washes on a FACSCalibur (BD Biosciences, San Jose, California, USA). To analyze IFN- $\gamma$ production, $T$ cells were stimulated directly ex vivo using antiCD3 (clone 2C11, Pharmingen) at a concentration of $0.1 \mu \mathrm{g} / \mathrm{ml}$ in $200 \mu \mathrm{l}$ of RPMI containing $2 \mu \mathrm{g} / \mathrm{ml}$ Brefeldin A (Sigma-Aldrich, St. Louis, Missouri, USA), 5\% FBS, $2 \mathrm{mM}$ L-glutamine, $20 \mathrm{mM}$ HEPES, and antibiotics for 6 hours at $37^{\circ} \mathrm{C}$ with $5 \% \mathrm{CO}_{2}$. Cells were then stained for CD4 or CD8, washed, fixed in $2 \%$ formaldehyde in PBS, permeabilized in $0.1 \%$ saponin in PBS containing 1\% FBS, and stained intracellularly for IFN- $\gamma$ (Pharmingen). The cells were then washed and resuspended in $2 \%$ formaldehyde before acquisition of 100,000-200,000 gated events on a FACSCAN flow cytometer and were analyzed using CellQuest software (BD Biosciences).

In vivo proliferation assay using BrdU. A BrdU (SigmaAldrich) solution of $0.8 \mathrm{mg} / \mathrm{ml}$ in sterile water was prepared fresh daily and supplied as drinking water during days 4-6 or days 6-8 after infection. Intracellular detection of BrdU was performed using reagents and protocols provided by the manufacturer (BrdU flow kit; PharMingen).

Statistical analyses. Data handling, analysis, and graphic representation was performed using SigmaStat (SPSS, Chicago, Illinois, USA) and Prism 2.01 (GraphPad Software, San Diego, California, USA).

\section{Results}

In these studies, CD46 transgenic mice were infected with MV 5 days before challenge with LM, and their spleen sizes and weights compared with those of age-matched naive and LM-infected mice that did not receive MV. Systemic infection with LM typically results in severe splenomegaly, with spleen weights 8 days after infection increasing by three- to fivefold above that of spleens from uninfected mice (Figure 1a). In marked contrast, if mice were concurrently infected with MV, then the size of the LM-infected spleen was significantly reduced ( $0.40 \mathrm{~g}$ vs. $0.29 \mathrm{~g}, P=0.009)$. These substantial differences in spleen size indicate that MV infection had a profound effect on the immune response to secondary bacterial infection.

We next measured LM CFUs in the spleens of mice infected in the presence or absence of concurrent MV infection to determine if MV had an effect on bacterial clearance. MV infection did not significantly alter LM growth kinetics at early time points (data not shown), but by 8 days after LM challenge, MV-infected mice had a significant sixfold higher LM titer than mice infected with LM alone $\left(6.3 \times 10^{3} \mathrm{CFUs} / \mathrm{g}\right.$ vs. $3.8 \times 10^{4}$ CFUs/g, $P=0.001$ ) (Figure $1 \mathrm{~b}$ ). We found no difference in LM growth kinetics in the livers of MVinfected mice (data not shown), which might be expected since there is a low-to-negligible degree of MV replication within this tissue (2).

To determine why LM clearance was delayed in MV-infected mice, we first examined the recruitment of effector cells of the innate immune system into the splenic compartment (Figure 2). Although macrophages $\left(\mathrm{CD} 11 \mathrm{~b}^{+}\right)$are initially targets of LM replication, on activation these cells become strongly bactericidal and contribute greatly to the subsequent control of LM growth in vivo. As compared with uninfected mice, in LM-infected mice there is about a fivefold increase in the number of CD $11 b^{+}$cells in the spleen by 8 days after infection. However, concurrent MV infection resulted in significantly fewer $\mathrm{CD} 11 \mathrm{~b}^{+}$cells accumulating in the spleen $(P=0.02)$ in response to the secondary bacterial infection (Figure 2a). The number of dendritic cells $\left(\mathrm{CD} 11 \mathrm{c}^{+}\right)$and NK cells $\left(\mathrm{DX}^{+}, \mathrm{CD3}^{-}\right)$in the spleens of LM-infected mice 8 days after infection increased only slightly above 

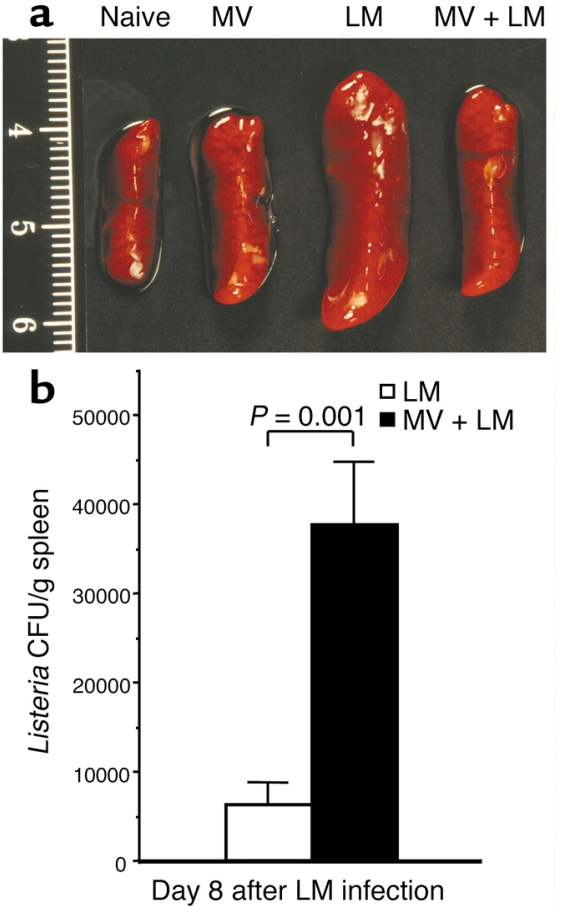

those observed in naive mice and were not significantly different from the numbers observed in LM-infected mice concurrently infected with MV (Figure 2, b and c). LM infection alone resulted in a sevenfold increase in neutrophils $\left(\mathrm{Gr}-1^{+} \mathrm{CD}^{-}\right)$in the spleen by 8 days after infection, and similar to the decrease in macrophage numbers, the recruitment of neutrophils was significantly reduced if LM-infected mice were infected with MV $(P=0.02)$ (Figure $2 \mathrm{~d})$. LM infection caused an increase in the total number of $\mathrm{CD}^{+} \mathrm{T}$ cells, $\mathrm{CD} 8^{+}$ $\mathrm{T}$ cells, and $\mathrm{B} 220^{+} \mathrm{B}$ cells in the spleen as compared with naive mice (increased by 0.23 -fold, 0.53 -fold, and

\section{Figure 1}

Concurrent $\mathrm{MV}$ infection impairs the clearance of $\mathrm{LM}$ from the host. YAC-CD46 transgenic mice were either untreated (naive), infected with $\mathrm{MV}$ alone, infected with $\mathrm{LM}$ alone, or infected with $\mathrm{MV}$ and 5 days later coinfected with LM. (a) LM-induced splenomegaly is reduced during acute $M V$ infection. Representative spleens were photographed 8 days after $L M$ infection (i.e., 13 days after $M V$ infection). Based on 6 to 21 samples per group, the average spleen weights $( \pm \mathrm{SD})$ were as follows: naive, $0.13 \pm 0.02 \mathrm{~g} ; \mathrm{MV}, 0.18 \pm 0.06$ g; LM, $0.40 \pm 0.15 \mathrm{~g}$; and MV and LM, $0.29 \pm 0.09 \mathrm{~g}$. Concurrent infection with $M V$ and $L M$ resulted in significantly reduced splenomegaly as compared with LM infection alone $(P=0.009$, Student's $t$ test). The scale on the left side of the figure is in centimeters. (b) Five days after MV infection, YAC-CD46 transgenic mice were coinfected with LM, and bacterial titers in the spleen were compared with those of mice that received LM in the absence of MV infection. Eight days after LM challenge, there was a sixfold increase in LM CFUs/g of spleen in mice concurrently infected with MV. This difference is statistically significant ( $P=0.001$, Student's $t$ test), indicating that coinfection with $M V$ resulted in an increased persistence of bacteria during secondary infection. The results show the average $( \pm$ SEM) of six mice per group. Equivalent results were observed in two additional experiments.

0.30-fold, respectively), but these numbers were not significantly altered by concurrent MV infection (data not shown). These studies indicate that MV suppresses the innate immune response mounted against a secondary bacterial infection, but the immunosuppression was not absolute. Innate effector cells that showed the highest increase in cell number during LM infection (macrophages and neutrophils) appeared to be the ones most strongly inhibited by MV, whereas the numbers of other cell types (dendritic cells and NK cells) were not greatly influenced by MV infection.

To explain the reduced numbers of $\mathrm{CD}_{11} \mathrm{~b}^{+}$ macrophages and $\mathrm{Gr}^{-} 1^{+} \mathrm{CD}^{-}$granulocytes, we tested for three potentially complimentary mechanisms. Reduction
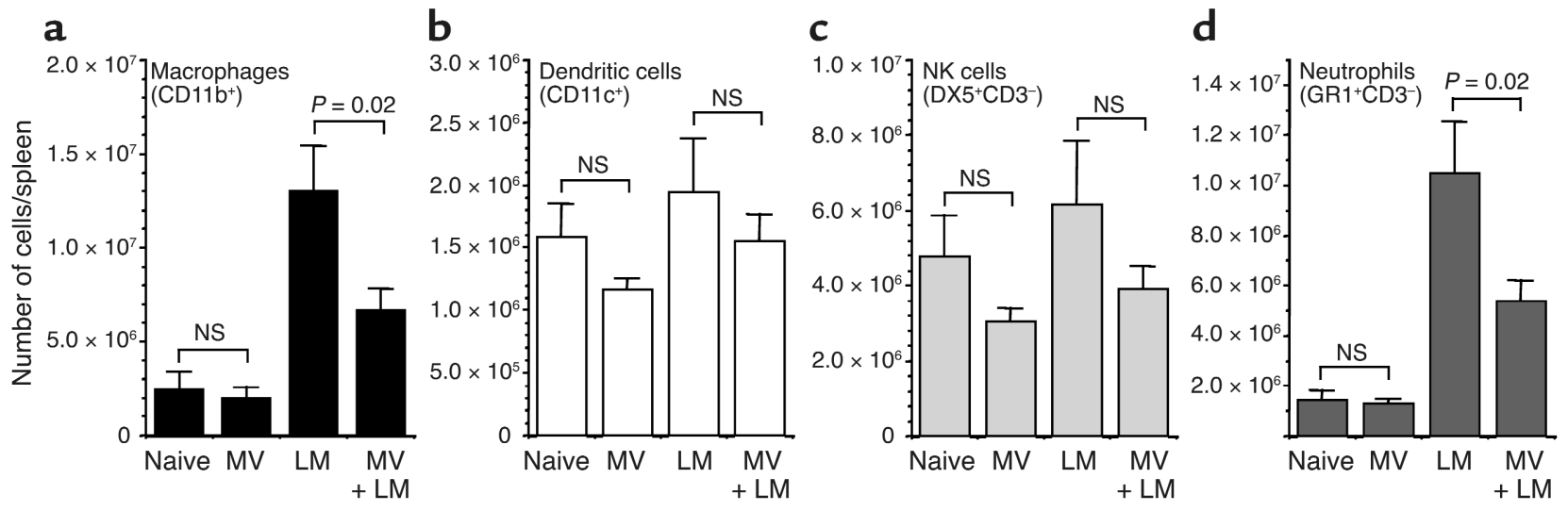

\section{Figure 2}

MV infection alters the recruitment of innate effector cells into the spleen after secondary infection with LM. Mice were either untreated (naive), infected with MV alone, infected with LM alone, or infected with MV and 5 days later coinfected with LM. Cell numbers were quantitated by flow cytometry 8 days after LM infection (i.e., 13 days after MV infection). The total numbers of cells expressing (a) CD11 $b^{+}$ (macrophages), (b) CD11 $\mathrm{c}^{+}$(dendritic cells), (c) DX5 ${ }^{+} \mathrm{CD} 3^{-}$(NK cells), and (d) Gr- $1^{+} \mathrm{CD} 3^{-}$(neutrophils) were calculated per spleen, and the average $( \pm$ SEM) of four to eight mice per group is shown. Statistical significance was determined using Student's $t$ test. Equivalent results were observed in two additional experiments. 

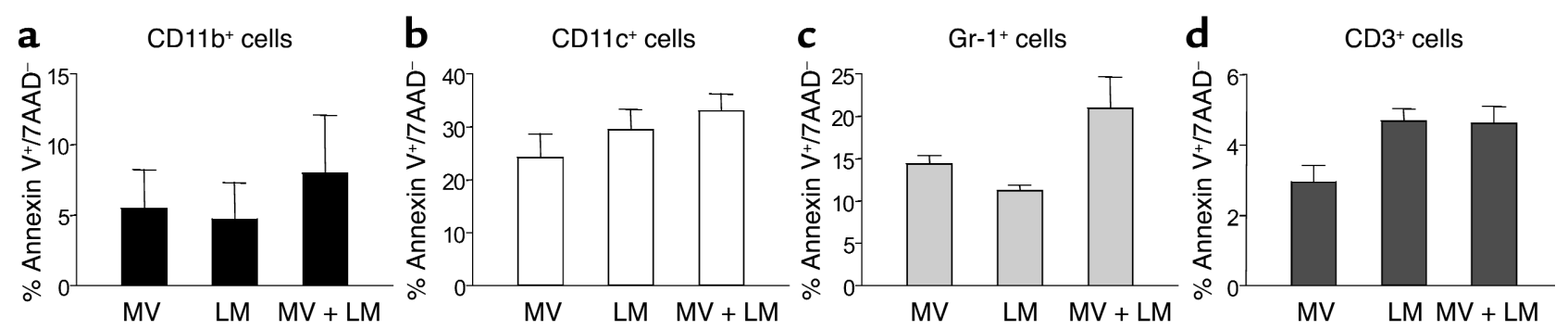

Figure 3

Minor alterations in apoptosis occur during concurrent MV infection. CD46 transgenic mice were infected with MV, LM, or MV and LM, and the levels of apoptosis occurring in vivo were determined 8 days after secondary bacterial infection (i.e., day 13 after primary $\mathrm{MV}$ infection). The degree of apoptosis was measured by quantitating the number of annexin $\mathrm{V}^{+} / 7 \mathrm{AAD}^{-}$cells in (a) CD11 b , (b) CD11 $\mathrm{c}^{+},(\mathbf{c}) \mathrm{Gr}-1^{+}$, and $($ d $) C D 3^{+} T$ cells. The results show the average $( \pm$ SEM) of three mice per group.

in splenic numbers of distinct immune cell populations during LM and MV infection may result from increased apoptosis, reduced proliferative expansion, or altered distribution of cells between lymphatic and nonlymphatic

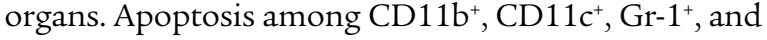
$\mathrm{CD}^{+}$cells was evaluated by annexin $\mathrm{V}$ staining. Enhanced apoptosis in MV-infected dendritic cells was reported earlier for in vitro studies $(23,24)$ and seen in our in vivo model. Likewise, $\mathrm{Gr}-1^{+}$cells showed a trend of increased apoptosis during concurrent MV and LM infections. However, the observed changes in apoptosis were subtle and not statistically different among mice infected with LM and MV, LM alone, or MV alone (Figure 3).

Proliferation was evaluated in vivo by an early (days 4-6) and a late (days 6-8) 48-hour pulse of BrdU. BrdU was administered by intraperitoneal injection $(1 \mathrm{mg})$ followed by $0.8 \mathrm{mg}$ of BrdU placed in the drinking water for the indicated periods of time. CD $11 b^{+}, \mathrm{CD} 11 \mathrm{c}^{+}, \mathrm{Gr}-1^{+}$, $\mathrm{CD}^{+}$, and $\mathrm{CD}^{+}$cells were segregated by FACS (Figure 4), and the number of BrdU-positive cells present in each population were identified using an antibody to BrdU (25). As shown in Figure 4, proliferation of CD11b ${ }^{+}$and $\mathrm{CD} 11 \mathrm{c}^{+}$cells was significantly reduced in mice infected with MV and LM as compared with mice infected with LM alone ( $P=0.003$ and $P=0.04$, respectively). Our findings in the CD46 MV transgenic model showing defects in the proliferation of macrophages $(2,26,27)$ have also been described in humans infected with MV. In contrast, no substantial decrease occurred in $\mathrm{Gr}-1^{+}$cells from $\mathrm{MV}$ and LM-infected mice as compared with mice infected with LM alone (data not shown). Compared with those from $\mathrm{LM}$-infected mice, $\mathrm{CD} 4^{+}$and $\mathrm{CD}^{+} \mathrm{T}$ cells from concurrently infected mice (MV and LM) exhibited a reduced proliferative response 4-6 days and 6-8 days after infection (Figure 4). At the earlier time points (4-6 days after infection), BrdU incorporation by $\mathrm{T}$ cells in concurrently infected mice was approximately half of that observed in mice infected with LM alone, and these differences approached statistical significance (CD8, $P=0.06$, and CD4, $P=0.05$ ). Although a decrease in $\mathrm{T}$ cell proliferation was also noted $6-8$ days after infection, these differences were not statistically significant (CD8, $P=0.23$, and CD4, $P=0.16$ ). Other experiments compared the differential distribution of macrophages, granulocytes, and $\mathrm{T}$ cells in blood, spleen, and mesenteric lymph nodes from LM-, LM- and MV-, and MVinfected mice. No significant differences were found among these three groups (data not shown). Hence, MV-induced immune suppression appeared to be mediated primarily by decreased proliferation/expansion of some, but not all, immunologically relevant cell types, rather than by an increased induction of apoptosis or altered distribution of these cells to other anatomical compartments such as the lymph nodes.

We next examined the effects of MV infection on adaptive cell-mediated immune responses by determining the IFN- $\gamma$-producing potential of both $\mathrm{CD}^{+}$and $\mathrm{CD}^{+} \mathrm{T}$ cells. Antigen-experienced T cells produce IFN- $\gamma$ directly ex vivo after anti-CD3 stimulation (28), and this assay
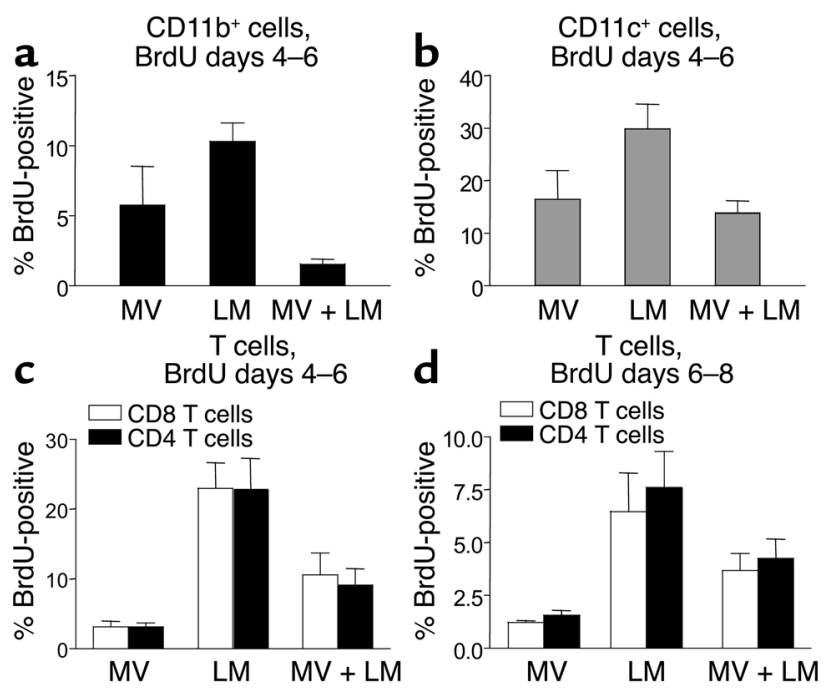

Figure 4

MV-induced immunosuppression results in reduced proliferative expansion of $C D 11 b^{+}$and $C D 11 c^{+} A P C s$ and $C D 3^{+} T$ cells. Studies were performed using transgenic mice expressing the $\mathrm{MV}$ receptor CD46 (7). These mice were infected with MV, LM, or MV and LM and given BrdU from days 4-6 after LM infection (days 9-11 after MV infection) (a-c), or BrdU was administered from days 6-8 after LM infection (d). Spleen cells were stained for CD11b (a), CD11c (b), or CD4 and CD8 (c and d) before permeabilization and staining for BrdU that was incorporated into the DNA of proliferating cells. The results show the average $( \pm$ SEM) of three mice per group. 


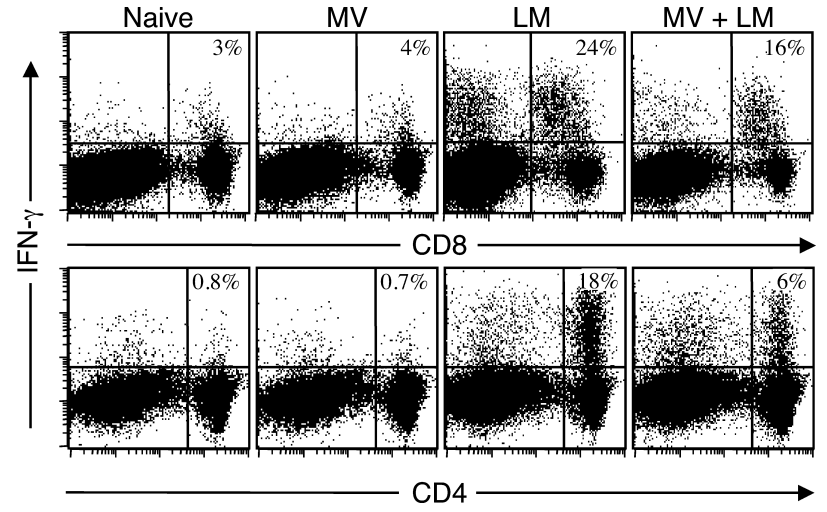

Figure 5

MV-induced immunosuppression results in a decreased frequency of IFN- $\gamma$-producing $T$ cells. T cell responses from naive mice were compared with mice infected with $\mathrm{MV}$, infected with $\mathrm{LM}$, or infected with MV and 5 days later coinfected with LM. T cell-mediated cytokine production was analyzed 8 days after LM infection (i.e., 13 days after $M V$ infection) by intracellular cytokine staining after 6 hours of direct ex vivo culture with anti-CD3. Less than $0.4 \%$ of $\mathrm{CD}^{+}$or $\mathrm{CD}^{+}{ }^{+} \mathrm{T}$ cells were IFN- $\gamma$ producing after 6 hours of in vitro culture without anti-CD3 stimulation (data not shown). Only a small percentage of $\mathrm{CD} 8^{+} \mathrm{T}$ cells or $\mathrm{CD} 4^{+} \mathrm{T}$ cells from naive or $\mathrm{MV}$ infected mice produced IFN- $\gamma$ after anti-CD3 stimulation. In contrast, LM infection resulted in a large percentage of $T$ cells that could be identified by IFN- $\gamma$ production after anti-CD3 stimulation. $\mathrm{MV}$ and LM coinfection resulted in a slight decrease in IFN- $\gamma$-producing $\mathrm{CD} 8^{+} \mathrm{T}$ cells $(P=0.09)$ but a significant reduction in the percentage of IFN- $\gamma$-producing $\mathrm{CD} 4^{+} \mathrm{T}$ cells $(P=0.02)$. Equivalent results were observed in two additional experiments.

was used to quantitate the number of $\mathrm{T}$ cells activated during LM infection in the presence or absence of a concurrent MV infection (Figure 5). The numbers of IFN- $\gamma$ producing $\mathrm{CD}^{+} \mathrm{T}$ cells identified after direct ex vivo stimulation were similar in naive and MV-infected mice $(4.1 \% \pm 1.1 \%$ and $3.5 \% \pm 1.2 \%$, respectively). In contrast, $22 \% \pm 8 \%$ of anti-CD3-stimulated $\mathrm{CD} 8^{+} \mathrm{T}$ cells produced IFN- $\gamma 8$ days after LM infection. Concurrent MV and LM infection resulted in a reduced percentage of IFN- $\gamma$-producing $\mathrm{CD}^{+} \mathrm{T}$ cells $(15.6 \% \pm 4.5 \%)$, but this reduction was not significantly different from the $\mathrm{CD}^{+} \mathrm{T}$ cell response of mice challenged with LM in the absence of MV infection $(P=0.09)$. Quantitation of IFN- $\gamma$-producing $\mathrm{CD}^{+} \mathrm{T}$ cells that simultaneously produced TNF- $\alpha$ also indicated a similar decrease in cytokine-producing potential (LM, 15.3\% IFN- $\gamma$ producing and TNF- $\alpha$ producing; LM and MV, $10.6 \%$ IFN- $\gamma$ producing and TNF- $\alpha$ producing). Only a small percentage $(<1 \%)$ of $\mathrm{CD}^{+} \mathrm{T}$ cells from either naive or MV-infected mice produced IFN- $\gamma$ after direct ex vivo stimulation with anti-CD3. In contrast, a relatively large percentage of $\mathrm{CD}^{+} \mathrm{T}$ cells $(14 \% \pm 8 \%)$ were activated by 8 days after LM infection to produce IFN- $\gamma$ after direct ex vivo stimulation. The percentage of IFN- $\gamma$-producing $\mathrm{CD}^{+}{ }^{+} \mathrm{T}$ cells in LM-infected mice that were concurrently infected with MV dropped by nearly threefold (to $6 \% \pm 2 \%$ ), indicating that MV infection significantly repressed the $\mathrm{CD}^{+} \mathrm{T}$ cell responses mounted during secondary bacterial infection
$(P=0.02)$. Quantitation of $\mathrm{CD} 4^{+} \mathrm{T}$ cells capable of dual IFN- $\gamma /$ TNF- $\alpha$ production also indicated a substantial decrease in antimicrobial cytokine production (LM, $11.7 \%$ IFN- $\gamma$ producing and TNF- $\alpha$ producing; $\mathrm{LM}$ and MV, $5.2 \%$ IFN- $\gamma$ producing and TNF- $\alpha$ producing). In addition, Figure $3 \mathrm{c}$ shows that MV also suppressed the proliferative expansion of $\mathrm{CD}^{+}$and $\mathrm{CD} 8^{+} \mathrm{T}$ cells after a pulse of BrdU during coinfection, demonstrating that MV dramatically altered both $T$ cell proliferation (Figure 4 ) and $T$ cell function (Figure 5).

\section{Discussion}

Our findings demonstrate that an acute, concurrent MV infection of CD46 transgenic mice results in an increased susceptibility to secondary bacterial infection. We found that MV increased the host's susceptibility to LM challenge and that this was associated with defects in both innate and adaptive immune responses that together lead to a defect in clearance of the bacterial infection. The results presented here lay the foundation for further studies into the mechanisms involved with MV-induced immune suppression as it relates to opportunistic infections, one of the main causes of mortality associated with MV infection in humans (8).

Our studies show that MV infection sharply decreased the innate immune response mounted against a secondary bacterial infection, but interestingly, the immunosuppression was not absolute. Our results indicate that the effector cells of the innate system that showed the highest increase in cell number during LM infection (macrophages and neutrophils) appeared to be the ones most strongly inhibited by MV infection, whereas the numbers of other cell types (dendritic cells and NK cells) were not greatly influenced by MV. Moreover, preliminary experiments have also revealed a substantial defect in the ability of neutrophils from MVand LM-infected mice to phagocytose $0.5-\mu \mathrm{m}$ YG fluorescently-labeled microspheres as compared with neutrophils from LM-infected animals (data not shown). Further biologic significance for our findings in the CD46-MV transgenic model is reflected by reports of defects in both neutrophils (29) and macrophages (26, 27) in humans infected with MV.

IFN- $\gamma$ plays a critical role in host resistance to primary $\mathrm{LM}$ infection (30). Antibacterial protection by $\mathrm{CD}^{+} \mathrm{T}$ cells is correlated with their ability to express this important inflammatory cytokine (31). This is likely to be due to the effects of IFN- $\gamma$ on macrophage activation (32) but may also be linked to the role of CD4-dependent help required for antibody production (33). $\mathrm{CD}^{+} \mathrm{T}$ cells, on the other hand, can provide immunity against LM either by IFN- $\gamma$ production or through perforinmediated lysis of infected cells $(31,34)$. Our results show that IFN- $\gamma$ production is significantly downregulated in $\mathrm{CD}^{+} \mathrm{T}$ cells and partially downregulated in $\mathrm{CD}^{+} \mathrm{T}$ cells (albeit not statistically significantly) after concurrent MV infection (Figure 5). These results provide strong evidence for MV-induced immune suppression of cell-mediated immunity during secondary infection. 
This, in turn, could be a contributing factor that also complements the observation of decreased innate antibacterial immunity, because IFN- $\gamma$ plays a critical role in macrophage activation (32). In addition, reduced $\mathrm{CD}^{+}$ $T$ cell responses could result in diminished antibacterial B cell-mediated immunity $(20,21)$, since CD4dependent help is required for optimal antibody responses $(33,35,36)$.

The ability to mimic MV-induced immunosuppression and susceptibility to secondary bacterial infection, using a small laboratory animal and Listeria as model for bacterial pathogenesis, provides a means to acquire the knowledge necessary to understand MVassociated mechanisms of disease and to develop effective treatments for this illness. Indeed, the novel availability of mice with genetic deficiencies of innate and/or adaptive immunity and the ability to complement those defects by immune reconstitution, coupled with the advantages of a reverse genetic system for MV (37), provides the opportunity to critically examine host-bacterial interactions with MV. For instance, is bacterial growth enhanced in cells that are coinfected with MV? Or is bacterial replication enhanced indirectly because of the suppressive effects of MV infection on normally bactericidal innate and adaptive immune responses? From our observations here, it appears clear that MV utilizes a multifactoral approach in aborting the host's immune system. Included in these MV-induced defects is a reduced proliferative expansion of CD11b, CD11c, CD8, and CD4 $\mathrm{T}$ cells and a sharp reduction in the ability of $\mathrm{CD} 4 \mathrm{~T}$ cells to secrete IFN- $\gamma$. All these factors in sum most likely act in a complementary way to suppress the immune response, giving a replicative advantage to a secondary bacterial agent that also coinfects the host.

\section{Acknowledgments}

This is publication 13932-NP from the Department of Neuropharmacology of the Division of Virology of the Scripps Research Institute. This research was supported by US Public Health grant AI36222 (to M.B.A. Oldstone), Oregon National Primate Research Center grant RR00163 (to M.K. Slifka), and NIH training grant AG00080 (to D. Homann).

1. Markowitz, L., and Katz, S. 1994. In Vaccines. S. Plotkin and B. Mortimer, editors. W.B. Saunders Co. Philadelphia, Pennsylvania, USA. 229-276.

2. Griffin, D.E., and Bellini, W.J., editors. 1996. Measles virus. LippincottRaven. Philadelphia, Pennsylvania, USA. 1267-1312.

3. Murray, C.J., and Lopez, A.D. 1997. Mortality by cause for eight regions of the world: Global Burden of Disease Study. Lancet. 349:1269-1276.

4. Oldstone, M.B.A. 1998. Viruses, plagues, and history. Oxford University Press. New York, New York, USA. 73-89.

5. Von Pirquet, C. 1908. Das verhalten der kutanen tuberculinreaktion wahrend der masern. Dtsch. Med. Wochenschr. 30:1297-1300.

6. McChesney, M.B., and Oldstone, M.B. 1989. Virus-induced immunosuppression: infections with measles virus and human immunodeficiency virus. Adv. Immunol. 45:335-380.

7. Oldstone, M.B., et al. 1999. Measles virus infection in a transgenic model: virus-induced immunosuppression and central nervous system disease. Cell. 98:629-640.
8. Beckford, A.P., Kaschula, R.O., and Stephen, C. 1985. Factors associated with fatal cases of measles. A retrospective autopsy study. S. Afr. Med. J. 68:858-863.

9. Manchester, M., and Rall, G.F. 2001. Model systems: transgenic mouse models for measles virus pathogenesis. Trends Microbiol. 9:19-23.

10. Mrkic, B., et al. 1998. Measles virus spread and pathogenesis in genetically modified mice. J. Virol. 72:7420-7427.

11. Shen, H., et al. 1995. Recombinant Listeria monocytogenes as a live vaccine vehicle for the induction of protective anti-viral cell mediated immunity. Proc. Natl. Acad. Sci. U. S. A. 92:3987-3991.

12. Slifka, M.K., et al. 1996. Antiviral cytotoxic T cell memory by vaccination with recombinant Listeria monocytogenes. J. Virol. 70:2902-2910.

13. Gugnani, H.C. 1999. Some emerging food and water borne pathogens. J. Commun. Dis. 31:65-72.

14. Elsner, H.A., Tenschert, W., Fischer, L., and Kaulfers, P.M. 1997. Nosocomial infections by Listeria monocytogenes: analysis of a cluster of septicemias in immunocompromised patients. Infection. 25:135-139.

15. Unanue, E.R. 1997. Inter-relationship among macrophages, natural killer cells and neutrophils in early stages of Listeria resistance. Curr. Opin. Immunol. 9:35-43.

16. Mackaness, G.B. 1962. Cellular resistance to infection. J. Exp. Med. 116:381-406

17. Kaufmann, S.H. 1993. Immunity to intracellular bacteria. Annu. Rev. Immunol. 11:129-163.

18. Pamer, E.G. 1993. Cellular immunity to intracellular bacteria. Curr. Opin. Immunol. 5:492-496.

19. Shen, H., Tato, C.M., and Fan, X. 1998. Listeria monocytogenes as a probe to study cell-mediated immunity. Curr. Opin. Immunol. 10:450-458.

20. Edelson, B.T., Cossart, P., and Unanue, E.R. 1999. Cutting edge: paradigm revisited: antibody provides resistance to Listeria infection. J. Immunol. 163:4087-4090.

21. Edelson, B.T., and Unanue, E.R. 2001. Intracellular antibody neutralizes Listeria growth. Immunity. 14:503-512.

22. Manchester, M., Liszewski, M.K., Atkinson, J.P., and Oldstone, M.B. 1994. Multiple isoforms of CD46 (membrane cofactor protein) serve as receptors for measles virus. Proc. Natl. Acad. Sci. U. S. A. 91:2161-2165.

23. Bhardwaj, N. 1997. Interactions of viruses with dendritic cells: a double-edged sword. J. Exp. Med. 186:795-799.

24. Fugier-Vivier, I., et al. 1997. Measles virus suppresses cell-mediated immunity by interfering with the survival and functions of dendritic and T cells. J. Exp. Med. 186:813-823.

25. Homann, D., Teyton, L., and Oldstone, M.B. 2001. Differential regulation of antiviral T-cell immunity results in stable CD8+ but declining CD4+ T-cell memory. Nat. Med. 7:913-919.

26. Esolen, L.M., Ward, B.J., Moench, T.R., and Griffin, D.E. 1993. Infection of monocytes during measles. J. Infect. Dis. 168:47-52.

27. Karp, C.L., et al. 1996. Mechanism of suppression of cell-mediated immunity by measles virus. Science. 273:228-231.

28. Nguyen, K.B., and Biron, C.A. 1999. Synergism for cytokine-mediated disease during concurrent endotoxin and viral challenges: roles for NK and $T$ cell IFN- $\gamma$ production. J. Immunol. 162:5238-5246.

29. Anderson, R., Rabson, A.R., Sher, R., and Koornhof, H.J. 1976. Defective neutrophil motility in children with measles. J. Pediatr. 89:27-32.

30. Buchmeier, N.A., and Schreiber, R.D. 1985. Requirement of endogenous interferon-gamma production for resolution of Listeria monocytogenes infection. Proc. Natl. Acad. Sci. U. S. A. 82:7404-7408.

31. Bhardwaj, V., Kanagawa, O., Swanson, P.E., and Unanue, E.R. 1998. Chronic Listeria infection in SCID mice: requirements for the carrier state and the dual role of $T$ cells in transferring protection or suppression. J. Immunol. 160:376-384.

32. Unanue, E.R. 1997. Studies in listeriosis show the strong symbiosis between the innate cellular system and the T-cell response. Immunol. Rev. 158:11-25.

33. Cobbold, S.P., Jayasuriya, A., Nash, A., Prospero, T.D., and Waldmann, H. 1984. Therapy with monoclonal antibodies by elimination of T-cell subsets in vivo. Nature. 312:548-551.

34. Harty, J.T., and Bevan, M.J. 1995. Specific immunity to Listeria monocytogenes in the absence of IFN-gamma. Immunity. 3:109-117.

35. Coulie, P.G., Coutelier, J.-P., Uyttenhove, C., Lambotte, P., and Van Snick, J. 1985. In vivo suppression of T-dependent antibody responses by treatment with a monoclonal anti-L3T4 antibody. Eur. J. Immunol. 15:638-640.

36. Vieira, P., and Rajewsky, K. 1990. Persistence of memory B cells in mice deprived of T cell help. Int. Immunol. 2:487-494.

37. Radecke, F., et al. 1995. Rescue of measles viruses from cloned DNA. EMBO J. 14:5773-5784. 